\title{
Correction to: The Role of Mediation in Development of Spatial and Math Abilities
}

\section{Correction to: \\ Chapter 17 in: D. Tzuriel, Mediated Learning and Cognitive Modifiability, Social Interaction in Learning and Development, https://doi.org/10.1007/978-3-030-75692-5_17}

The original version of the chapter was inadvertently published with an incorrect Figure 17.7, which has now been corrected. The affected chapter and the book have been updated with the changes. 


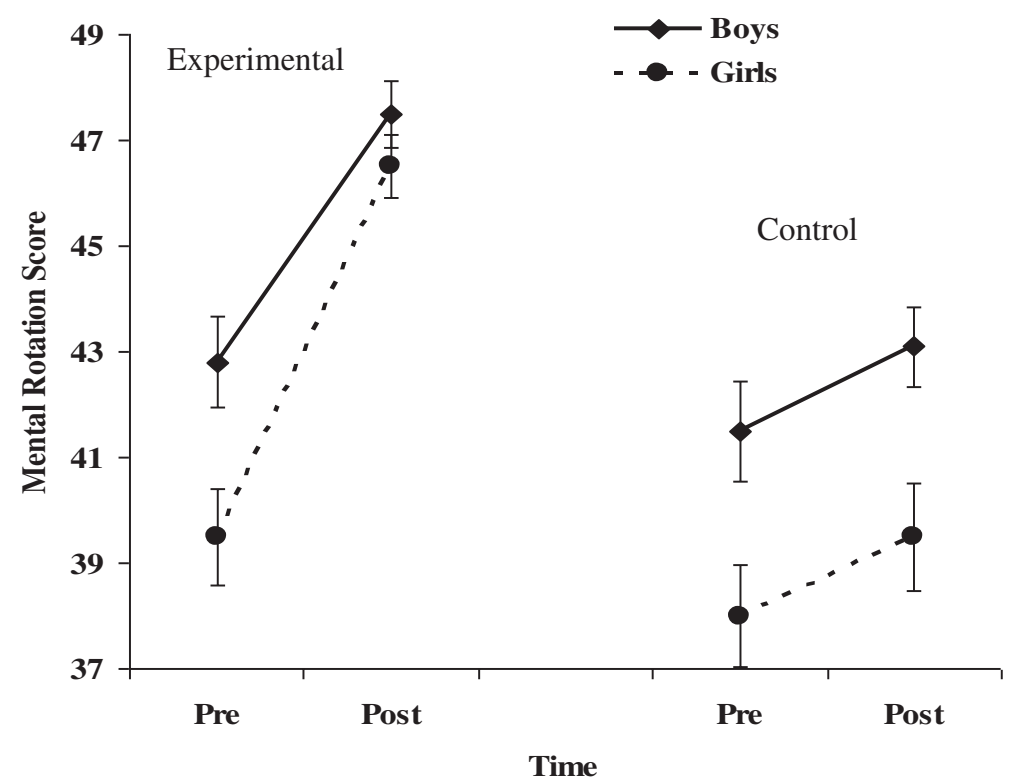

Fig. 17.7 Pre- and Post-Teaching Performance on Mental Rotation among Boys and Girls in the Experimental and Control Groups (Reproduced by permission from Child Development, 2010, $81,1417-1430)$ 